\title{
Self-Esteem in a German Population Sample of Children and Adolescents: Association with Demographic and Psychosocial Variables
}

\author{
Birgit Kröner-Herwig*, Jennifer Maas and Philipp Reckling
}

Department of Clinical Psychology and Psychotherapy, Georg-Elias-Müller Institute of Psychology, University of Germany, Germany

*Corresponding author: Birgit Kröner-Herwig, Department of Clinical Psychology and Psychotherapy,Georg-Elias-Müller Institute of Psychology, University of Germany, Germany , Tel: 0049-551-393581; E-mail: bkroene@uni-goettingen.de

Received date: May 06, 2014, Accepted date: September 05, 2014, Published date: September 09, 2014

Copyright: @ 2014 Birgit Kröner-Herwig et al. This is an open-access article distributed under the terms of the Creative Commons Attribution License, which permits unrestricted use, distribution, and reproduction in any medium, provided the original author and source are credited.

\begin{abstract}
Research has shown that high self-esteem (SE) is a core feature of psychological health and well-being. A population sample of German youths $(11-16$ years, $n=3509)$ was surveyed in 2 waves regarding SE and various demographic and psychosocial variables assumed to be related. Parents' reports were also gathered about their children. Mean SE-scores indicated a generally high level of SE in the sample. Girls displayed significantly lower SE than boys with an effect size of $d=0.34$. Moderate to strong associations were found with satisfaction in different domains of life, with the highest correlation found for appearance and the lowest for health. Girls were in general more dissatisfied with life. Internalizing and also externalizing were negatively correlated with SE, particularly in girls. Also a higher level of somatic symptoms was associated with lower SE. A prospective analysis revealed that dysfunctional parenting and family climate significantly predicted SE explaining more than $20 \%$ of variance in SE in girls, but only $10 \%$ in boys. Structural social data (e.g. SES) did not impact SE. The study confirmed the significant role of SE for psychological and somatic well-being and the relevance of familial interaction in its formation. The observed gender differences underline the necessity to undertake sex specific analyses in this area of research. Prospective research should be expedited.
\end{abstract}

Keywords: Self-esteem; Life-satisfaction; Psychological symptoms; Risk analysis; Gender

\section{Introduction}

Positive self-esteem (SE) is assumed to be a powerful protective characteristic, endowing children and adolescents with resources for coping with the demands and stressors of daily life. High SE correlated with psychological well-being [1-3] and even with physical health [3, 4-6]. The aim of this epidemiological study was to examine SE in a randomly selected large German population sample regarding its relationship with sex and age, and its associations with life-satisfaction, psychological symptoms of internalizing, externalizing and indices of somatic health, including amount of sportive or physical activities as well as body mass index (BMI). Under a prospective perspective, we were interested in the prediction of SE by different psychosocial variables, i.e. parenting style, family climate, single parent household and socioeconomic status (SES). Many prior studies have dealt with SE in pediatric samples, however, there is little information on German children and adolescents on this subject especially regarding recent research. Additionally, deficient prospective research has been conducted in this field. We examined whether hypotheses suggested by earlier studies can be confirmed in our German sample assessed during the late first decade of the 21st century, i.e. in spite of the sociocultural and time difference. Furthermore, a main focus was on the prediction of SE by potential psychosocial risk variables. Thus, findings should enable us to evaluate the stability of the construct and its linkage to other psychosocial factors under different and changed conditions.

\section{Hypotheses}

SE of German youths was examined regarding the following assumptions.

\section{Girls show lower SE than boys.}

In a meta-analysis on gender differences, Kling et al. [7] found a small gender effect favoring boys. In subsequent studies, conflicting data was found. Specifically, Benjet and Hernandez-Guzman [8] reported no gender differences in prepubertal Mexican youths as well as Erkut et al. [9] among Puerto Rican children. In more recent studies, the findings of the earlier meta-analysis were supported [10-13]. Our study examined whether this more recent trend can be confirmed in a large population sample from a central European country, especially regarding girls still living with the disadvantage of a weaker self-concept.

\section{There is a decline in SE with age during adolescence.}

A decline over time was observed by Burnett [14] when comparing elementary school and middle school children. Israel and Ivanova [12] also reported age differences in their sample of obese youths, as did Barber, Hall and Armistead [15] among two age groups of African Americans. This decline can be interpreted as the result of challenging social demands on youth which increases during adolescence. Thus, a lower SE was expected among the older age groups and a decline of SE in the last two assessment periods in our German sample.

\section{An interaction effect of age and sex in SE can be observed}

Two earlier studies $[13,16]$ identified an interaction between sex and grade. We sought to examine whether we could observe different 
trajectories of SE in girls and boys with increasing age suggesting a different cognitive processing style regarding daily life affairs.

Significant associations between SE and satisfaction in different domains of life are expected. Correlations should differ between domains and sexes.

SE and life-satisfaction are closely related constructs, but as previously shown [17], they should be distinguished. We expected SE to be closely correlated with general life-satisfaction and explored whether different domains of personal values and goals were differently associated with SE, possibly denoting particularly relevant domains regarding self-concept. Furthermore, we examined whether the profile of associations differs between sexes $[13,18]$. In particular, it was expected that satisfaction with appearance would be more closely associated with SE in girls than in boys, and that it would be more strongly associated with SE in all children than satisfaction with other domains.

Body mass index (BMI) significantly correlates with SE. The correlation should be higher in girls.

As an "objective" and probably very salient aspect of appearance, BMI was assessed. Obesity in children and adolescents has become a severe health problem internationally [19]. It may also have become a growing challenge regarding self-evaluation and a possible threat to SE, since it is broadly discussed in public as a major blemish. Findings from recent studies found that not the objective weight status but the perceived or subjective weight status correlated with SE [20]. A review [21] also suggested lower levels of SE in "objectively" obese youths. However, the main variables used in these studies, i.e. self-reported limitations in competencies attributed to obesity, were different from our more global measure of SE. We expected a significant moderate association between an objective index of being (over)weight with SE, and also sex differences in the size of the correlation.

The level of physical activities is expected to positively correlate with SE.

It is assumed that physical activity fosters a positive self-concept (SE) by reinforcing the perception of a fully functioning body as a significant part of the self. This was supported by a recent study on young soccer players from different European countries not including Germany [22].

Internalizing and externalizing (measured by self- and parental report) and SE are significantly associated. In this regard, differences between girls and boys are expected.

Depression and anxiety driven cognitive and behavioral processing, often labeled "internalizing" (INT), is more distinct in girls, as a review showed [23]. Some studies found an association between depressive symptoms and low SE in schoolchildren grades 3 to 6 [24] and in adolescents [25]. A Swiss epidemiological study [26] reported distinctly low SE in severely depressed children (12-17 years old). We examined the relation of this trait variable in a nonclinical population sample where the average level of internalizing should be rather low, to find out whether under these conditions a link between both variables can also be found. Moreover, we assumed that the correlation would be higher in girls.

The cluster of hyperactive and aggressive aspects of behavior and cognitive-emotional expression of anger and frustration, known as "externalizing" (EXT), is more prevalent in boys $[23,27]$. The relation of EXT to SE seems complex, as some authors suggested "paradoxical" effects [28,29] when comparing self-report data and parental ratings of EXT. We wanted to clarify this effect by examining the interaction of sex and source of information (self-report and parent-report) expecting a higher correlation between self-report of EXT and SE, since EXT symptoms could be less threatening to the affected individual than to others.

\section{Somatic health is significantly associated with SE.}

Whereas the association of psychological health and SE is both very plausible and relatively well documented, the relation to somatic aspects of health was less well examined, though links have been found $[3,5]$. Different indicators of physical health and different sources of information were analyzed. Thus, we were able to look from different perspectives at this phenomenon.

\section{Prediction of SE}

A main objective of the study was to find out whether psychosocial variables, previously found to play a crucial role in the development of SE in children and adolescents, will predict SE at a later point in time and whether sex differences regarding the power of the prediction can be found. We made use of two post-assessment periods so that the stability of the prediction could be evaluated.

Dysfunctional parenting styles significantly predict SE in children at a later point of time (1-2 years after baseline).

A number of studies found significant associations between parental traits or behaviors and SE in children [10,15,30,31]. However, longitudinal designs have only rarely been used to study genuine predictive effects. Thus a dysfunctional style of parenting like frequent blame, inconsistency and restrictiveness was hypothesized to predict frictions in the parent/child interaction and negatively impact children's SE.

A negative family climate significantly predicts low SE at a later time.

As argued above, SE should partly be determined by variables from the family environment. Poor family integration and low family support predicted low SE in children, whereas cohesion showed a positive association [32-35]. We operationalized poor family climate as a lack of cooperative problem-solving strategies in the family and low level of common activities. A low level of a positive family climate was expected to be deleterious for SE in the children.

A significant negative influence of living in a single parent household and low SES on SE was expected.

We also examined whether more structural social aspects of family can influence SE. There were only few studies on this topic. A low correlation with SES was documented in a meta-analysis [36]. As the occurrence of single-parent households has increased over the years, the question of whether there is a significant link with SE has become more ardent. Pike [37] did not find any differences in SE between Australian children living in a one-parent household, and those raised in a "complete" household thus not supporting the wide spread assumption that this circumstance brings disadvantages for the child. The analysis of our large population sample should add new evidence regarding the so far ambiguous results. 


\section{Method}

\section{Sample characteristics}

The study sample consisted of a general population cohort of families (German citizens) with at least one child between the ages of 7-14 for the first wave of the survey. A sample of 8,800 families residing in four districts of Southern Lower Saxony was randomly drawn from the described group who were registered in community files. The surveys were mailed via the postal service and the families (children and parents) were prepared for the questionnaires with an introductory letter informing them of a research project on the status of pediatric health, particularly headache (for further details see [38]). The survey comprised four annual waves with data for the current study mostly from waves 3 and 4 (W3/W4). Potential predictors of SE were taken from W2. Children between 11 and 16 years of age completed a self-report inventory of SE. Data on SE from W3 was available from 3,509 and in W4 from 3,283 individuals. Sex was nearly evenly distributed with a small preponderance of girls (male: W3= $49.6 \%$; W4 $=48.7 \%$ ). Three age groups were compared (based on age in W3): 11-12 years $(\mathrm{n}=944), 13-14$ years $(\mathrm{n}=964)$ and $14-16$ years $(\mathrm{n}=864)$.

\section{Assessment of psychosocial variables}

All six items of the subscale self-esteem ("Selbstwert") taken from the Questionnaire of Self-and Competence Perception for Children (Fragebogen zur Erfassung von Selbst- und Kompetenzeinschätzungen bei Kindern) [39] were used for the assessment. The original scale had demonstrated a Cronbach's a of .60. In contrast with the original questionnaire, a 5-point rating scale was used for item response and the total score was based on self-ratings only (example: "I would like to be different from what I am."; response scale: (5) not at all - (1) very much so; items were negatively poled). In the current study, reliability ranged from good to satisfactory (Cronbach's $\alpha$ : W3/4 $=.74 / .76$ ). All examined variables had similar alpha scores for both waves of assessment so only the consistency scores from W3 will be reported. Higher total scores indicate more positive SE. Life-satisfaction (Cronbach's $\alpha=.74$ ) from the German version of the Child Health Questionnaire [40] was rated by the children on four domains: performance in school, sports, friendship, appearance and health. A general appreciation of life-satisfaction was also assessed (response scale ranging from (1) not at all satisfied - (5) very much satisfied). INT and EXT were measured by selected items from the Youth SelfReport (YSR) [41] validated for youths between 11 and 18 years. INT (example: "I felt guilty") comprised eight items. EXT (example: "I cannot sit still for a long time") was assessed with six items. Contrary to the original form (3-point rating scale), responses were scaled on a 5 -point scale ((1) never - (5) always). Cronbach's a demonstrated good homogeneity of the short scales: INT: $\alpha=.86$, EXT: $\alpha=.78$.

The correlation between the short scale and the total scale assessed in a subgroup of participants was high (.86). Ratings by parents on their children's characteristics were also collected (Cronbach's $\alpha$ : $\mathrm{INT}=.84 ; \mathrm{EXT}=.78)$. Dysfunctional parenting style (W3; $\alpha=.74)$ was measured by six items from the Inventory of Parenting Styles [42]. The items represented parental blame, inconsistency and restriction, (example: "My mother / father tells me I am a nuisance."; 5-point rating scale (1) never - (5) always)). Family climate was measured by five items (example: "We are satisfied with our family activities."; "We solve our problems by talking about them."). Items were taken from the Mannheim Parent Interview [43]. A 5-point rating scale was used
((1) never - (5) always; a higher score indicating better family climate). A Cronbach's $\alpha$ of .77 was obtained for the parental scale and $\alpha=.67$ for the children's scale. A somatic symptom index (SSI) was defined as the sum of 9 items reporting symptoms experienced in the last six months at least "sometimes" (score 3 on a 5-point rating scale): abdominal pain, back pain, headache, no appetite, sleeplessness, gastrointestinal dysfunctions, fatigue, nausea or vomiting, and earache. Reports from the parents on these items were also gathered. Moreover a global evaluation of their child's health by the parents (response scale: (1) very good to (5) very bad) was also assessed.

Phys-Act was determined by 11 items of the Self-Administered Physical Activity Checklist (SAPAC) [44] presenting 11 items (example: "to go swimming," with a 5-point rating scale: 'less than once/week'- 5 times/week'). The resulting index consisted of physical activities exhibited at least more than once per week. BMI was calculated on the basis of weight and height information from the parents and was taken from W3.

\section{Statistical analysis}

Group differences (sex, age, assessment waves) were analyzed by ANOVA, associations between variables, by the Spearman rank correlation, and the size of correlation coefficients were compared by Fisher Z-test Predictors were identified by linear regression analyses. An alpha level of $\mathrm{p}=.01$ was set to compensate for not using a Bonferroni correction procedure. The number of subjects (Ss, only those participating in W3 and W4) included in the analyses differed according to missing data points across time-dependent analyses including only those children who participated in W3 and W4.

\section{Results}

\section{$\mathrm{SE}$ and its relation to sex and age}

SE was not distributed normally; negative moderate skewness $(\geq-.70)$ with a negative kurtosis $(\geq .090)$ was found. About $60 \%$ of the sample had high mean SE scores of $\geq 4$ (scale 1-5). Mean values of SE were close to 4. A 3-factor ANOVA (sex $\mathrm{x}$ age group $\mathrm{x}$ assessment wave) revealed a highly significant sex effect $(\mathrm{F}(1,1420)=81.51$, $\mathrm{p}=.000)$ as girls reported a lower $\mathrm{SE}$ than boys with effect sizes ranging from $\mathrm{d}=0.32(\mathrm{Mf} / \mathrm{W} 3=3.86(.72) / \mathrm{Mm} / \mathrm{W} 3=4.09(.64))$ to $\mathrm{d}=0.34$ $((\mathrm{Mf} / \mathrm{W} 4=3.84(.74) / \mathrm{Mm} / \mathrm{W} 4=4.08(.65)$; Table 1$)$. There were no significant main effects of wave or age group and no interaction effects (all p > 0.05). However, a direct comparison of age groups (ANOVA, post-hoc test) revealed that the youngest group (11-12years) showed higher SE than both older groups.

\section{Associations of SE with variables of life-satisfaction}

Correlational findings are given in Table 2 for W3 and W4. Results for W4 are only described if they differed from W3 because in general, they were very similar (Table 2). Descriptive data are given in Table 1.

SE and general life-satisfaction correlated substantially, $\rho=.54$ (Table 2). The domain specific correlations of life-satisfaction and SE were highest for appearance (W3; $\rho=.52$ ) and lowest for health $(\rho=.29)$. These correlations differed significantly (Z-test, $p=.000)$, while others in the area of life-satisfaction did not. The separate analysis of girls and boys revealed a very similar profile regarding different life domains (Table 2) found in both waves. Only regarding satisfaction relating to appearance and school did the correlation differ significantly between girls and boys (W3; Z-test: $\mathrm{p}=0.001$ ). In $\mathrm{W} 4$, the 
Citation: Kröner-Herwig B, Maas J, Reckling P (2014) Self-Esteem in a German Population Sample of Children and Adolescents: Association with Demographic and Psychosocial Variables. J Child Adolesc Behav 2: 158. doi:10.4172/jcalb.1000158

coefficients no longer differed (Table 2). Another significant difference

between sexes was found in general life satisfaction in association with SE.

\begin{tabular}{|c|c|c|c|c|c|c|}
\hline & \multicolumn{2}{|l|}{ Total } & \multicolumn{2}{|l|}{ Boys (1) } & \multicolumn{2}{|l|}{ Girls (2) } \\
\hline & \multicolumn{2}{|l|}{ M (SD) } & \multicolumn{2}{|l|}{$M(S D)$} & \multicolumn{2}{|l|}{ M (SD) } \\
\hline & W3 & W4 & W3 & W4 & W3 & W4 \\
\hline BMI (P) & $19.11(3.36)$ & $19.79(3.55)$ & $19.18(3.47)$ & $19.9(3.6)$ & 19.04(3.24) & $19.68(3.5)$ \\
\hline $\begin{array}{l}\text { Dysfunctional Parenting } \\
\text { (W2) }\end{array}$ & $1.95(0.57)$ & $1.95(0.57)$ & $1.97(0.59)$ & $1.91(0.58)$ & $1.93(0.55)$ & $1.95(0.55)$ \\
\hline $\begin{array}{l}\text { Externalizing } \\
\text { (C) }\end{array}$ & $1.77(0.55)$ & $1.59(0.49)$ & $1.78(0.59)$ & $1.61(0.53)$ & $1.75(0.51)$ & $1.56(0.46)$ \\
\hline $\begin{array}{l}\text { Externalizing } \\
\text { (P) }\end{array}$ & $1.79(0.56)$ & $1.4(0.46)$ & $1.86(0.61)$ & $1.49(0.5)$ & $1.71(0.49)$ & $1.32(0.39)$ \\
\hline $\begin{array}{l}\text { Family climate } \\
\text { (W2) }\end{array}$ & $3.77(0.78)$ & $3.76(0.78)$ & $3.75(0.77)$ & $3.75(0.77)$ & $3.78(0.79)$ & $3.78(0.79)$ \\
\hline Health $(P)$ & $1.65(0.58)$ & $1.69(0.56)$ & $1.64(0.56)$ & $1.67(0.55)$ & $1.66(0.59)$ & $1.71(0.57)$ \\
\hline $\begin{array}{l}\text { Internalizing } \\
\text { (C) }\end{array}$ & $1.73(0.58)$ & $1.74(0.6)$ & $1.62(0.53)$ & $1.6(-0.52)$ & $1.83(0.61)$ & $1.88(0.64)$ \\
\hline Internalizing $(P)$ & $1.62(0.53)$ & $1.54(0.53)$ & $1.58(0.51)$ & $1.5(0.5)$ & $1.66(0.55)$ & $1.58(0.54)$ \\
\hline Physical activities & $3.54(0.89)$ & $3.38(0.91)$ & $3.7(0.89)$ & $3.52(0.9)$ & $3.38(0.87)$ & $3.25(0.9)$ \\
\hline Physical symptoms (C) & $1.82(0.48)$ & $1.85(0.49)$ & $1.71(0.44)$ & $1.72(0.43)$ & $1.92(0.5)$ & $1.97(0.51)$ \\
\hline Somatic symptoms (P) & $1.62(0.46)$ & $1.66(0.5)$ & $1.57(0.43)$ & $1.58(0.45)$ & $1.67(0.48)$ & $1.73(0.53)$ \\
\hline Self-esteem (C) & $4.04(0.64)$ & $3.92(0.7)$ & $4.09(0.64)$ & $4.08(0.65)$ & $3.86(0.72)$ & $3.84(0.74)$ \\
\hline Single parent household & Yes:13.5\% & --- & $13.10 \%$ & --- & $14 \%$ & --- \\
\hline Socioeconomic Status & $\begin{array}{l}\text { U: } 50 \% \\
\text { M: } 45.4 \% \\
\text { L: } 4.7 \%\end{array}$ & --- & $\begin{array}{l}50 \% \\
45.40 \% \\
4.50 \%\end{array}$ & --- & $\begin{array}{l}50 \% \\
45.30 \% \\
4.80 \%\end{array}$ & --- \\
\hline $\begin{array}{l}\text { (C)= Children's ratings (self- } \\
\text { U: upper class; M: middle cl } \\
--- \text { W3 equal to W4 }\end{array}$ & $\begin{array}{l}\text { report), }(P)= \\
\text { ass; L: lower c }\end{array}$ & tings & & & & \\
\hline
\end{tabular}

Table 1: Descriptive Statistics: M (SD)

\begin{tabular}{|c|c|c|c|c|c|c|}
\hline $\mathbf{N}: \max / \min$ & 2906-2916 & $1500-1193$ & $1407-1417$ & 2901-2916 & $1487-1498$ & $1407-1417$ \\
\hline Correlating variables & Total & Girls & Boys & Total & Girls & Boys \\
\hline Life-satisfaction (C) & W 3 & W3 & W3 & W4 & W4 & W4 \\
\hline - school & $.34^{\star}$ & 0.38 & $.31 \#$ & 0.38 & 0.35 & 0.38 \\
\hline - sports & 0.32 & 0.33 & 0.29 & 0.33 & 0.35 & 0.33 \\
\hline - friendship & 0.31 & 0.31 & 0.31 & 0.33 & 0.32 & 0.36 \\
\hline - appearance & 0.52 & 0.56 & $.45 \#$ & 0.51 & 0.53 & 0.5 \\
\hline - health & 0.29 & 0.31 & 0.26 & 0.28 & 0.25 & 0.3 \\
\hline
\end{tabular}


Citation: Kröner-Herwig B, Maas J, Reckling P (2014) Self-Esteem in a German Population Sample of Children and Adolescents: Association with Demographic and Psychosocial Variables. J Child Adolesc Behav 2: 158. doi:10.4172/jcalb.1000158

Page 5 of 10

\begin{tabular}{|c|c|c|c|c|c|c|}
\hline General life satisfaction & 0.54 & 0.56 & 0.5 & 0.55 & 0.66 & $.53 \#$ \\
\hline Phys. activities (C) & 0.15 & 0.11 & 0.14 & 0.13 & 0.11 & 0.12 \\
\hline BMI (P) & -0.15 & -0.21 & $-.10 \#$ & -0.15 & -0.18 & -0.16 \\
\hline INT (C) & -0.55 & -0.55 & $-.51 \#$ & $-.61 \# \#$ & -0.61 & -0.58 \\
\hline INT (P) & -0.33 & -0.35 & -0.31 & -0.36 & -0.37 &.-33 \\
\hline EXT (C) & -0.4 & -0.39 & -0.4 & -0.43 & -0.48 & -0.47 \\
\hline EXT (P) & -0.18 & -0.2 & -0.21 & -0.18 & -0.21 & -0.22 \\
\hline Som. symp. (C) & -0.41 & -0.41 & -0.37 & -0.41 & -0.46 & $-.37 \#$ \\
\hline Som. symp. (P) & -0.29 & -0.27 & -0.19 & -0.27 & -0.27 & $-.18 \#$ \\
\hline Health $(P)$ & -0.18 & -0.19 & -0.16 & -0.19 & -0.25 & $-.17 \#$ \\
\hline Prediction from W2 (n) & 2329-2824 & $1193-1444$ & $1388-1424$ & $2343-2847$ & $1201-1459$ & $1142-1224$ \\
\hline DysParent (C) & -0.27 & -0.32 & $-.23 \#$ & -0.32 & -0.3 & $-.21 \#$ \\
\hline Family climate (C) & 0.37 & 0.38 & $.29 \#$ & 0.45 & 0.38 & $.26 \#$ \\
\hline Single parent $(P)$ & $-.02 \mathrm{~ns}$ & $-.07 \mathrm{~ns}$ & $-.06 \mathrm{~ns}$ & $-.07 \mathrm{~ns}$ & $-.01 \mathrm{~ns}$ & -.07 \\
\hline SES (P) & $-.11 \mathrm{~ns}$ & $-.05 \mathrm{~ns}$ & $-.07 \mathrm{~ns}$ & $-.05 \mathrm{~ns}$ & $-.02 \mathrm{~ns}$ & $-.01 \mathrm{~ns}$ \\
\hline \multicolumn{7}{|c|}{ * all corr. except those notified as "ns", significant at $p<0.001$; } \\
\hline \multicolumn{7}{|c|}{ \# Significant differences between girls and boys in the correlation coeff. (Z-Tests, $p<0.05)$} \\
\hline \multicolumn{7}{|c|}{ \#\# Significant effect of time of assessment } \\
\hline
\end{tabular}

Table 2: Correlations (rho) and regression coefficients: self-esteem and its association with different psychosocial variables

ANOVAs on life-satisfaction scores including general life and all domain specific scores revealed highly significant time effects showing a decrease of satisfaction in W4, except for the appearance domain which did not reach significance (Table 3). Also, significant sex differences were seen in nearly all analyses, except for the domain of school and friendship. In all others domains, girls reported higher dissatisfaction. In general life-satisfaction, a significant interaction effect was found (Table 3) with girls being less satisfied than boys and becoming even more dissatisfied over time than boys $(\mathrm{Mf} / \mathrm{w} 3=4.33$ (. 93), $\mathrm{Mm} / \mathrm{W} 3=4.42(.82) / \mathrm{Mf} / \mathrm{W} 4=4.16(.99), \mathrm{Mm} / \mathrm{W} 4=4.35(.84)$.

\begin{tabular}{|c|c|c|c|c|c|c|}
\hline \multirow[t]{2}{*}{ variables / effects } & \multicolumn{2}{|l|}{ Wave } & \multicolumn{2}{|l|}{ Sex } & \multicolumn{2}{|c|}{ Interaction } \\
\hline & $F(d f)$ & $\mathbf{p}$ & $F(d f)$ & p & $F(d f)$ & $\mathbf{p}$ \\
\hline \multicolumn{7}{|l|}{ satisfaction } \\
\hline \multirow[t]{2}{*}{ school } & 10.19 & \multirow[t]{2}{*}{0.001} & & 0.92 & \multirow[t]{2}{*}{$<1$} & 0.59 \\
\hline & $(1 / 2945)$ & & & $\mathrm{ns}$ & & ns \\
\hline \multirow[t]{2}{*}{ sports } & \multirow[t]{2}{*}{$46.56(1 / 2947)$} & \multirow[t]{2}{*}{0} & 44.91 & \multirow[t]{2}{*}{0} & \multirow[t]{2}{*}{3.95} & 0.047 \\
\hline & & & $(1 / 2947)$ & & & ns \\
\hline \multirow[t]{2}{*}{ friendship } & 11.26 & \multirow[t]{2}{*}{0.001} & \multirow[t]{2}{*}{$<1$} & 0.47 & \multirow[t]{2}{*}{$<1$} & 0.56 \\
\hline & $(1 / 2945)$ & & & ns & & ns \\
\hline \multirow[t]{2}{*}{ appearance } & 5.56 & 0.018 & 37.66 & \multirow[t]{2}{*}{0} & \multirow[t]{2}{*}{1.71} & 0.19 \\
\hline & (1/2928) & ns & $(1 / 2928)$ & & & ns \\
\hline
\end{tabular}


Citation: Kröner-Herwig B, Maas J, Reckling P (2014) Self-Esteem in a German Population Sample of Children and Adolescents: Association with Demographic and Psychosocial Variables. J Child Adolesc Behav 2: 158. doi:10.4172/jcalb.1000158

Page 6 of 10

\begin{tabular}{|c|c|c|c|c|c|c|}
\hline \multirow[t]{2}{*}{ health } & 36.27 & \multirow[t]{2}{*}{0.001} & 10.41 & \multirow[t]{2}{*}{0.001} & \multirow[t]{2}{*}{2.03} & 0.16 \\
\hline & (1/2937) & & (1/2937) & & & ns \\
\hline \multirow[t]{2}{*}{ general } & 43.51 & \multirow[t]{2}{*}{0} & 25.28 & \multirow[t]{2}{*}{0} & 7.54 & \multirow[t]{2}{*}{0.006} \\
\hline & $(1 / 2940)$ & & (1/2940) & & $(1 / 2940)$ & \\
\hline
\end{tabular}

Table 3: Results for ANOVA (sex x wave) on life-satisfaction scores

For descriptive reasons, scores were categorized according to the level of dissatisfaction within each area. Ss who had responded with 4 or 5 (partly dissatisfied/ very dissatisfied) were grouped as "dissatisfied" and the percentage of dissatisfied was calculated. The number of Ss expressing dissatisfaction was highest in the domain school (Table 4; W4: 17.2\%) and lowest in the domain friendship (W3:
4.3\%). Across both sexes, $5.4 \%$ of the children were dissatisfied with life in general (W3). When comparing girls to boys, the percentage of dissatisfied children was always higher for girls (Table 4) as results of ANOVA had already shown. The percentage of dissatisfied was always higher in W4 with the exception of girls regarding the domain appearance.

\begin{tabular}{|c|c|c|c|c|c|c|}
\hline \multirow{3}{*}{$\begin{array}{l}\text { Domains of satisfaction } \\
\text { dissatisfaction * }\end{array}$} & \multicolumn{2}{|c|}{ total subjects $\%$} & \multicolumn{2}{|c|}{ girls \% } & \multicolumn{2}{|c|}{ boys $\%$} \\
\hline & \multicolumn{2}{|c|}{$\mathrm{n}=3305$} & \multicolumn{2}{|c|}{$n=1695$} & \multicolumn{2}{|c|}{$n=1610$} \\
\hline & W 3 & W 4 & W 3 & W 4 & W 3 & W 4 \\
\hline school & 14.6 & 17 & 15.7 & 17.4 & 13.5 & 16.4 \\
\hline sports & 8.6 & 10.3 & 11 & 12.8 & 6.2 & 7.6 \\
\hline friendship & 4.4 & 4.9 & 5.2 & 5.8 & 3.4 & 4 \\
\hline appearance & 7.8 & 8.2 & 11.6 & 10 & 4 & 6.5 \\
\hline health & 7.8 & 8.9 & 9.4 & 10.3 & 6.2 & 7.4 \\
\hline life satis. general & 5.4 & 6.3 & 6.9 & 8.2 & 3.7 & 4.2 \\
\hline \multicolumn{7}{|c|}{ *Cronbach's alpha over all domains $\geq .72$} \\
\hline \multicolumn{7}{|c|}{ \# partially dissatisfied (4) and very dissatisfied (5) } \\
\hline
\end{tabular}

Table 4: Percentage of subjects dissatisfied with the specific domain of the self or environment (response score $\geq 4$ )

\section{SE and other associated variables}

In the total sample, associations between SE and INT and EXT (see Table 2) reported by the children were negative and of considerable size for both waves $\left(\mathrm{W} 3\right.$; $_{\mathrm{INT}}=-.55$; $_{\mathrm{EXT}}=-.33$ ). The correlations with EXT were significantly lower than those with INT (Z-test, all $\mathrm{p}=\leq$. 001). The correlations in W3 and W4 did not differ much between sexes (Z-tests: ns). We found a higher correlation only for INT in W4 (-.61) than in W3 $(Z \leq 0.01)$. Parents' rating of INT and EXT were significantly less closely correlated with SE than children's selfreported INT (all Z-tests, $\mathrm{p}<$. 01).

The BMI in both waves correlated significantly but weakly with SE (W3; rho = -.15). A significant difference was found between boys and girls with a higher coefficient in girls $(\mathrm{p}<.05)$ but it vanished in W4.

The number of physical activities was significantly but only weakly correlated with SE, with no difference between sexes and waves (all $\mathrm{Z} \geq 0.05$ ).
Indices of health, e.g. the somatic symptoms score collected from the children and from the parents, were relatively closely associated with SE, differing between sexes. When the number of adverse somatic symptoms rose, the child's SE decreased (Table 2). In every case, girls showed higher correlations.

Much higher associations were found regarding self-report compared to parents' report. A rating of global health was obtained only from the parents which was also correlated with SE $(Z<0.001)$, but less strongly when compared with the symptom score, even when only parents' report was considered.

\section{Prediction of SE from wave 2 variables}

Dysfunctional parenting style, as reported by the children in W2, significantly predicted SE in W3 explaining 7.1\% (W3; Table 2) of the variance. Family climate had a higher predictive power explaining $13.7 \%$ of the variance in W3. The coefficients did not differ between girls and boys. Both predictors explained less variance in W4 compared to W3 (Table 2). SES and a single-parent family were not 
significantly associated with SE which did not differ between waves and sexes (see Table 2).

In a multiple regression analysis, the predictors above maintained their statistical power and explained a total of $22.6 \%$ of the variance in SE with family climate as the strongest predictor $(\beta=.24$ dysfunctional parenting: $\beta=-.14$ ) The results were almost identical in W4. The explained variance was considerably larger in girls than boys (W3: $\mathrm{R} 2=22.6 \% / \mathrm{R} 2=10 \%)$.

\section{Discussion}

\section{SE and sex and age}

In total, the sample was characterized by rather high SE, with an average score clearly above the midpoint of the scale. Scores were not normally distributed, with high scores being the most frequent, and small standard deviations. We had information showing that the sample was in some respects not representative of the population though the participants were randomly selected from registries. The lower SES group was clearly underrepresented in favor of high and middle status groups. But since there was no correlation between SE with SES, the biased distribution of SE scores cannot be accounted for simply by this fact.

SE significantly differed between sexes with girls reporting lower SE than boys. Thus, our hypothesis based on the finding of a metaanalysis [7] was confirmed by this study. Obviously adolescent girls in the late first decade of the 21 st century seem to still be more selfcritical and questioning of their worth and merits than boys. It has been suggested that this is not mainly the consequence of a less positive evaluation by significant others in their social environment, but a consequence of a habitually more negative cognitive-emotional processing of events of life and also the self. This is in accord with the fact that there was a strong correlation of SE with INT, comprehending negative affectivity and a tendency towards selfblame. This type of processing is also evident in the variable satisfaction with life, where girls were the most dissatisfied in general and in each domain.

The size of this sex effect, $\mathrm{d}=.34$, was a little larger compared to the previous meta-analysis $(\mathrm{d}=.26)$, so there was apparently no "closing the gap" between sexes in spite of a development favoring girls in school regarding performance evaluation and grades in the last decades (at least within the German education system). Future research should examine whether this constellation also appears in other countries.

Contrary to our prediction, there was no significant effect of age on SE although the youngest group (11-12 year old) showed the expected highest SE score. The size of the effect, comparing their score to both older groups, was small $(\mathrm{d}=.16 / .23)$, documenting no decrease in SE over time. Also no interaction of sex and age could be identified. When the intra-individual changes in SE over all Ss between W3 and W4 were assessed, no significance was found, denoting that in the course of one year SE was stable.

One could speculate that the climax of negative or lower SE is already reached at an age of 13 or 14 years in concordance with the assumption that the change to adult role comes earlier than before. However, this hypothesis could only be supported by a more differentiated analysis of time effects.

\section{SE and life-satisfaction}

Regarding the association of SE and life-satisfaction, we found the expected moderate to high positive correlations. Thus, the two constructs shared a large amount of variance. Looking at different domains of life, satisfaction with personal appearance was the most important domain influencing SE to a considerable extent. It was the most closely associated domain of satisfaction for all girls and boys. As expected, girls were more sensitive to supposed deficits in appearance than boys as depicted by significantly higher correlations among girls. However, the difference between sexes was statistically significant only in W3, since appearance became more closely linked to SE in boys a year later. We cannot decide on the basis of our data, whether this was a reliable finding regarding the course of development, that in boys appearance becomes more important at a later age compared to girls.

Also school influenced the self-concept of girls to a greater extent than boys, signaling that achievement motivation may be higher in school girls. Regarding this domain, a similar time trend was seen. School became more important for self-concept in boys during the second assessment period when the participants were a year older.

Satisfaction with health showed the weakest association with SE, but, nevertheless, it was within the range of the other domains. Children and adolescents are less aware of the importance of health, especially when they are in rather good health. This contrasts somewhat to the relatively high correlation found between selfreported somatic symptoms and SE (> .40). This seems to signify that when the abstract concept of health becomes operationalized by perceivable and bothering symptoms, health becomes a concrete and emotionally connoted state and thus more closely attached to selfconcept.

No other area of life than school was more openly discussed as a major stressor for youth in the German society, and indeed we found the highest dissatisfaction rates in both girls and boys, reaching $17 \%$ in the total sample in W4. Though data did not provide information on the sources of dissatisfaction, the raw number raises concern, i.e. that school characteristics may endanger the SE of many pupils. However, the association of SE and school dissatisfaction was not closer than others in other areas of life (Table 2).

There was also a distinct trend of increased dissatisfaction in nearly all areas of life by the 4 th assessment period. In the domain of appearance, we found a somehow differential trend for boys and girls. Whereas dissatisfaction increased in boys from $\mathrm{W} 3$ to $\mathrm{W} 4$, it decreased in girls. This trend, however, should be evaluated on the basis that many more girls were dissatisfied with their appearance than boys with the largest difference between them (11.4\% vs. $4 \%)$. Though in all domains girls were more dissatisfied, this difference was the largest found. More than $5 \%$ of all children were dissatisfied with life in general - a percentage which increased when asked again one year later (6.3\%).

The described time trend was much more pronounced in the dissatisfaction scores than was evident in the SE scores. This seemed to indicate, that the tendency to criticize (maybe not only in questionnaires!) aspects of daily life becomes more pronounced, the older the children get, whereas self-evaluation with is a more sublime and private process not so much contingent on external circumstances. 


\section{SE and psychological and psychosomatic characteristics}

A main interest of the study was the analysis of associations describing the links between SE and different psychological trait variables. Close links were found with INT, hardly differing between assessment points and sexes. Thus, for both sexes a higher level of negative affectivity was associated with low SE. We already discussed the character of this psychological variable as an early appearing disposition with some genetic background, probably linked to female sex. Indeed, as in other studies, a higher level of INT was seen in girls than in boys with an effect size of $d=.37$. EXT was significantly associated with SE signifying that a tendency to respond with anger, hyperactivity and aggressiveness was associated with lower SE. However, associations were distinctly lower than with INT which seemed to be a much more endangering cognitive-emotional processing strategy regarding SE. The correlations of SE with INT and EXT were stronger when the children themselves reported their psychological functioning compared to parents' report. The fact that significant correlations were maintained when using parents' report, however, speaks for the validity of the findings not being solely dependent on a bias due to the source of information.

We did not find the paradoxical effect regarding EXT other authors alluded to. Instead of a lower correlation of self-reported EXT to SE compared to parents' report, the contrary was found. The assumed effect that higher EXT was disregarded by the afflicted and not related to SE contrary to the parents' evaluation did not appear.

Our data showed in general that with regard to cognitive-emotional processing which is not always or consistently linked to observable behaviors, data should possibly be retrieved from the subjects themselves.

While a moderate to strong correlation between SE and psychological dysfunctions was expected, the link with somatic dysfunction had only been examined by a few studies. As already discussed, we found a considerable association between child reported somatic symptoms and SE. Children plagued by recurrent irritating symptoms like headache, back pain or vomiting showed less selfacceptance. There were also significant differences between boys and girls with girls showing a higher number of symptoms, as found in most studies, and a closer correlation with SE. As observed before, the girls' SE was more strongly influenced by negative self-evaluation than the boys, even concerning the somatic condition. The correlation between SE and parental report of somatic symptoms in their children underlined the validity of the finding. One should take note of the fact that physical symptoms were generally correlated with psychological traits like catastrophizing, INT and similar traits [45].

Physical activity level was significantly correlated to SE, but had a very small influence, not differing between sexes and assessment periods, i.e. it was nearly irrelevant for the self-concept at least in this population sample.

Whereas in girls the BMI correlated with SE with $\rho=-.21$, i.e. a higher body weight impacted SE negatively, a significantly lower coefficient of -.10 was found for boys. Consequently, body weight was less relevant for the self-concept of boys already indicated by findings on life-satisfaction. No time difference in the size of the correlation was found regarding appearance.

\section{The prediction of SE by psychosocial characteristics}

Four social, respectively psychosocial variables were analyzed as potential predictors of SE. Unexpectedly, SES and also living in a single-parent household did not contribute to a lower SE in the children and adolescents similar to an Australian sample [37]. Thus, limited financial means in a single parent household as well as being in a low SES group and the occurrence of other associated distress factors, did not threaten a positive self-concept in the youths, at least in this sample where low status families were underrepresented. In this respect the public worry regarding the increase in single-parent families seemed to be justified by the data of the studies from Germany and Australia.

The study, however, demonstrated that psychosocial family characteristics influenced SE. A positive family climate, where problems are solved by talking about them and pleasant activities are shared, fosters SE. Obviously, when children and adolescents experience positive appreciation and respect from their parents they were able to build a positive concept of their self. Thus it can be seen as a strong protective factor for children's self-concept, maybe even in the long run. On the contrary, dysfunctional parenting styles undermine SE in the children, as previously reported [16].

Based on the smaller regression coefficients, this negative feature of the child-parent interaction was less influential than the contribution of a positive family atmosphere. Interestingly, in most cases negative interaction patterns seemed to exhibit more influence (e.g. expressed emotions). The impact of family factors was distinctly stronger in girls. Girls were obviously more sensitive to the quality of familial interaction than boys.

\section{Limitations}

Self-report data of children and adolescents were only available from children older than 9 years (in W2 as baseline). Therefore no conclusions about associations of variables and predictions can be drawn about younger children (below 11 years). Also we did not apply the complete self-report scale of SE in all phases of assessment. Thus a 4 -wave longitudinal data evaluation could not be conducted. A further limitation included the assessment of INT and EXT based on shortened versions of the original scales. However, their validity had been confirmed [46].

Another limitation, already mentioned, may be the distribution of SES groups in our sample, with high and middle status groups being overrepresented.

With the exception of the prospective analysis of potential psychosocial risk factors for low SE, we willingly denounced a more complex strategy of statistical analysis, i.e. multivariate regression analysis, which may under a specific perspective be seen as a limitation. Regarding correlational analyses we were genuinely interested in the association of different variables, with overlapping variances but differential constructs, with SE. To our understanding, this procedure warrants a content focused interpretation of results. It is evident, that most variables used - if not all - shared more or less common variance correlating with one another in different ways. However, our main directive was not to determine the total amount of variance explained by all included variables, controlling for shared variances and then identifying the strongest independent predictors. Rather, we wanted to describe the net of links of SE to certain other variables. Furthermore, the heterogeneity of variables used did not allow for integration into a coherent theory. Therefore, we did not have a convincing model for multivariate analysis. 
This was different in the prospective analysis where a block of associated risk factors should be analyzed in a meaningful multivariate fashion, to determine the common explained variance by these neighboring constructs and enables singling out the most potent of these predictors.

\section{Summary and Conclusions}

A population based sample of children and adolescents (11 - 17 years) was characterized by a distinctly positive SE with about $60 \%$ reaching scores $\geq 4$ ( $\max$. 5). The observed sex difference with lower self-esteem in girls supports findings from a more than a decade old meta-analysis. These findings are best explained by a stable tendency for girls to be more censorious and derogatory towards themselves and feature more negative affectivity, associated with an INT style of processing. This negative cognitive-emotional tendency is not only directed towards the self but also becomes apparent in the evaluation of nearly all domains of life. It was speculated that this is a consequence of an internal disposition and not strongly determined by particular negative psychosocial life conditions. In other words it may evidence a high sensitivity to social stressors of daily life in girls with the consequence of a more distinct negative affect.

In agreement with the finding that appearance was more relevant for SE for girls, BMI was more closely linked to SE in girls than boys. However the association of body weight was less distinct than expected. The positive impact of engaging in physical activities - which were rather limited - for the global SE in the current population sample was minute.

Children with lower SE were characterized by a higher level of EXT, but less so compared to INT. The associations between low SE and dysfunctional processing were more pronounced when self-report of children was used, but findings were not attributable to bias only as parental data confirm it. Altogether psychological as well as somatic well-being was confirmed as a correlate of less positive SE.

Features of family interaction predicted more than $22 \%$ of the variance in SE, i.e. the quality of family interaction was quite important for SE in children whereas structural social factors like SES and a single parent household had little influence. Data suggested that girls were much more sensitive to adverse and also positive influences of family regarding their self-concept.

These findings were based on a population study with a relative low level of dysfunctional psychosocial features with a small variance in variables tending to suppress the size of correlations.

The results highlighted the need for more research regarding the factors influencing SE since more than $75 \%$ of the variance remained unexplained. The authors would expect personal rather than external factors to be worthy of analysis: self-efficacy in different areas of life and also unfavorable stress-coping strategies. Since SE itself is a core feature of the individual closely linked to mental and physical wellbeing, pediatric research should spend more effort on prospective studies.

\section{Acknowledgements:}

This Research is supported by the German Federal Ministry of Education and Research (BMBF) and we acknowledge support by the Open Access Publication Funds of the Göttingen University.

\section{References}

1. Bednar RL, Wells MG, Peterson SR (1989) Self-esteem: Paradoxes and innovations in clinical theory and practice. The American Psychological Association, Washington DC.

2. Kashani JH, Beck NC, Hoeper EW, Fallahi C, Corcoran CM, et al. (1987) Psychiatric disorders in a community sample of adolescents. Am J Psychiatry 144: 584-589.

3. Orth U, Robins RW, Widaman KF (2012) Life-span development of selfesteem and its effects on important life outcomes. J Pers Soc Psychol 102: 1271-1288.

4. Antonucci TC, Jackson JS (1983) Physical health and self-esteem. Family \& Community Health: The Journal of Health Promotion \& Maintenance 6: 1-9.

5. Li HC, Chan SL, Chung OK, Chui ML (2010) Relationships among mental health, self-esteem and physical health in Chinese adolescents: an exploratory study. J Health Psychol 15: 96-106.

6. Vingilis E, Wade TJ, Adlaf E (1998) What factors predict student selfrated physical health? J Adolesc 21: 83-97.

7. Kling KC, Hyde JS, Showers CJ, Buswell BN (1999) Gender differences in self-esteem: a meta-analysis. Psychol Bull 125: 470-500.

8. Benjet C, Hernandez-Guzman L (2001) Gender differences in psychological well-being of Mexican early adolescents. Adolescence 36: 47-65.

9. Erkut S, Szalacha LA, García Coll C, Alarcón O (2000) Puerto Rican Early Adolescents' Self-Esteem Patterns. J Res Adolesc 10: 339-364.

10. Ackard DM, Neumark-Sztainer D, Story M, Perry C (2006) Parent-child connectedness and behavioral and emotional health among adolescents. American Journal of Preventive Medicine 30: 59-66.

11. Derdikman-Eiron R, Indredavik MS, Bratberg GH, Taraldsen G, et al (2011) Gender differences in subjective well-being, self-esteem and psychosocial functioning in adolescents with symptoms of anxiety and depression: Findings from the Nord-Trøndelag Health Study. Scandinavian Journal of Psychology 52: 261-267.

12. Israel AC, Ivanova MY (2002) Global and dimensional self-esteem in preadolescent and early adolescent children who are overweight: Age and gender differences. International Journal of Eating Disorders 31: 424-429.

13. Wang L (2005) Correlations between self-esteem and life satisfaction in elementary school students. Chinese Mental Health Journal 19: 745-749.

14. Burnett PC (1996) Gender and grade differences in elementary school childrens' descriptive and evaluative self-statements and self-esteem. School Psychology International 17: 159-170.

15. Barber CN, Hall J, Armistead L (2003) Parent-adolescent relationship and adolescent psychological functioning among African-American female adolescents: Self-esteem as a mediator. Journal of Child and Family Studies 12: 361-374.

16. Heaven P, Ciarrochi J (2008) Parental styles, gender and the development of hope and self-esteem. Europeran Journal of Personality 22:707-724.

17. Huebner ES, Gilman R, Laughlin JE (1999) A multimethod investigation of the multidimensionality of children's well-being reports: Discriminant validity of life-satisfaction and self-esteem. Social Indicators Research 46: $1-22$.

18. McCauley Ohannessian C, Lerner RM, Lerner JV, von Eye A (1999) Does self-competence predict gender differences in adolescent depression and anxiety? J Adolesc 22: 397-411.

19. Ogden CL, Carroll MD, Kit BK, Flegal KM (2012) Prevalence of obesity and trends in body mass index among US children and adolescents, 1999-2010. JAMA 307: 483-490.

20. Ali MM, Fang H, Rizzo JA (2010) Body weight, self-perception and mental health outcomes among adolescents. J Ment Health Policy Econ 13: 53-63.

21. Griffiths LJ, Parsons TJ, Hill AJ (2010) Self-esteem and quality of life in obese children and adolescents: a systematic review. Int J Pediatr Obes 5: 282-304. 
Citation: Kröner-Herwig B, Maas J, Reckling P (2014) Self-Esteem in a German Population Sample of Children and Adolescents: Association with Demographic and Psychosocial Variables. J Child Adolesc Behav 2: 158. doi:10.4172/jcalb.1000158

Page 10 of 10

22. Athanasious G, Papaioannou P R, Appleton M T, Jowett G E, Bosselut G et al. (2013) Moderate-to-vigorous physical activity and personal wellbeing in European youth soccer players: Invariance of physical activity, global self-esteem and vitality across five countries. International Journal of Sport and Exercise Psychology 11: 351-364.

23. Leadbeater BJ, Blatt SJ, Quinlan DM (1995) Gender-linked vulnerabilities to depressive symptoms, stress, and problem behaviors in adolescents. Journal of Research on Adolescence 5: 1-29.

24. AlGhamdi S, Manassis K, Wilansky-Traynor P (2011) Self-perception in relation to self-reported depressive symptoms in boys and girls. J Can Acad Child Adolesc Psychiatry, 20: 203-207.

25. Brage D, Meredith W (1994) A causal model of adolescent depression. J Psychol 128: 455-468.

26. Steinhausen H-C, Metzke C (2000) Adolescent self-rated depressive symptoms in a Swiss epidemiological study. Journal of Youth and Adolescence 29: 427-440.

27. Hicks BM, Blonigen DM, Kramer MD, Krueger RF, Patrick CJ, et al. (2007) Gender differences and developmental change in externalizing disorders from late adolescence to early adulthood: A longitudinal twin study. J Abnorm Psychol 116: 433-447.

28. Diamantopoulou S, Rydell AM, Henricsson L (2008) Can both low and high self-esteem be related to aggression in children? Social Development 17: 682-698.

29. Baumeister RF, Smart L, Boden JM (1996) Relation of threatened egotism to violence and aggression: the dark side of high self-esteem. Psychol Rev 103: 5-33

30. Bámaca MY, Umaña-Taylor AJ, Shin N, Alfaro EC (2005) Latino adolescents' perception of parenting behaviors and self-esteem Examining the role of neighborhood risk. Family Relations 54: 621-632.

31. Felson RB, Zielinski MA (1989) Children's self-esteem and parental support. Journal of Marriage \& the Family 51: 727-735.

32. Axinn WG, Barber JS, Thornton A (1998) The long-term impact of parents' childbearing decisions on children's self-esteem. Demography 35: 435-443.

33. Cooper JE, Holman J, Braithwaite VA (1983) Self-esteem and family cohesion: The child's perspective and adjustment. Journal of Marriage and the Family 45: 153-159.

34. Enright KM (2001) Family factors and self-esteem in gifted versus nongifted children. Dissertation Abstracts International Section A: Humanities and Social Sciences 62: 1-790.
35. Lee HE (2008) A study of the relationship between self-esteem and perceived family environment in fourth, fifth, and sixth grade children attending Korean Baptist Churches in the Dallas-Fort Worth area. Dissertation Abstracts International Section A: Humanities and Social Sciences, 69, 1-880.

36. Twenge JM, Cambell WK (2002) Self-esteem and socioeconomic status: A meta-analytic review. Personality and Social Psychology Review 6: 59-71.

37. Pike LT (2003) The adjustment of Australian children growing up in single-parent families as measured by their competence and self-esteem. Childhood 10: 181-200.

38. Kröner-Herwig B, Heinrich M, Morris L (2007) Headache in German children and adolescents: a population-based epidemiological study. Cephalalgia 27: 519-527.

39. Wünsche P, Schneewind K A (1989) Entwicklung eines Fragebogens zur Erfassung von Selbst- und Kompetenzeinschätzungen bei Kindern (FSKK). Diagnostica 35: 217-235.

40. Landgraf JM, Maunsell E, Speechley KN, Bullinger M, Campbell S, et al. (1998) Canadian-French, German and UK versions of the Child Health Questionnaire: methodology and preliminary item scaling results. Qual Life Res 7: 433-445.

41. Achenbach TM (1991) Manual for the Youth Self-Report and 1991 Profile. Burlington: University of Vermont, Department of Psychiatry.

42. Krohne HW, Pulsack A (1995) Das Erziehungsstil-Inventar (ESI). Weinheim: Beltz.

43. Esser G, Blanz B, Geisel B, Laucht M (1989) Mannheimer Elterninterview (MEI). Weinheim: Beltz.

44. Prochaska JJ, Sallis JF, Griffith B, Douglas J (2002) Physical activity levels of Barbadian youth and comparison to a U.S. sample. Int J Behav Med 9: 360-372.

45. Kröner-Herwig B, Gassmann J (2012) Headache disorders in children and adolescents: their association with psychological, behavioral, and socio-environmental factors. Headache 52: 1387-1401.

46. Fernandez Castelao C, Kröner-Herwig B (2013) Different trajectories of depressive symptoms in children and adolescents: predictors and differences in girls and boys. J Youth Adolesc 42: 1169-1182. 